\title{
Terahertz analysis of an East Asian historical mural painting
}

\author{
K. Fukunaga \\ kaori@nict.go.jp
}

\section{Hosako}

\section{Y. Kohdzuma}

\section{T. Koezuka}

\author{
M.-J. Kim
}

T. Ikari

X. Du

\author{
National Institute of Information and Communications Technology, Tokyo, Japan \\ National Institute of Information and Communications Technology, Tokyo, Japan \\ Nara National Research Institute for Cultural Properties, Nara, Japan \\ Nara National Research Institute for Cultural Properties, Nara, Japan \\ Kyoto University, Kyoto, Japan \\ Nara National Research Institute for Cultural Properties, Nara, Japan \\ Spectra Design, Tochigi, Japan \\ Inner Mongolia Museum, Hohhot, China
}

Terahertz ( $\mathrm{THz})$ spectroscopy and THz imaging techniques are expected to have great potential for the non-invasive analysis of artworks. We have applied THz imaging to analyse the historic mural painting of a Lamaism temple by using a transportable time-domain THz imaging system; such an attempt is the first in the world. The reflection image revealed that there are two orange colours in the painting, although they appear the same to the naked eye. THz imaging can also estimate the depth of cracks. The colours were examined by X-ray fluorescence and Raman spectroscopy, and the results were found to be in good agreement. This work proved that THz imaging can contribute to the non-invasive analysis of cultural heritage. [DOI: 10.2971/jeos.2010.10024]

Keywords: terahertz, cultural heritage, nondestructive test, mural painting

\section{INTRODUCTION}

Scientific analysis is essential to be carried out so as to preserve cultural heritage objects, and various common instruments such as an X-ray fluorescence spectrometer have been used to identify materials in the artworks [1]. Although precise analysis including electron probe micro analysis of the cross section can be performed when the sampling is allowed, non-destructive observation is desired, especially for fragile artworks in the East Asian countries.

Nara Research Institute for Cultural Properties, The Inner Mongolia Museum, and China National Institute of Cultural Property organised a collaborative research on the wall paintings of Dazhao Monastrey, which is the largest and bestpreserved monastery in Hohhot, Inner-Mongolia province. The construction of the temple was completed in 1580 during the Ming Dynasty (1368-1644) and it is therefore the oldest Lamaist Buddhist temple in Inner Mongolia. The east and west walls had wall paintings that reached $20.3 \mathrm{~m}$ each in height. Almost all paintings were removed from the wall in 1980s and are preserved in The Inner Mongolia Museum in Hohhot city.

Analytical measures used in 2005 were a portable spectrophotometer (Konica Minolta, Model CM-2022), a microscope, X- ray fluorescence spectrometer (XRF, OURSTEX, Model 100FS), and a Laser Raman Analyser (Turbo Optex, HRam-200) of which the wavelength was $785 \mathrm{~nm}$ in 2002 [2].

Recently, THz spectroscopy and imaging techniques have been progressed rapidly $[3,4]$. THz waves $(0.1-10 \mathrm{THz})$ are non-invasive, can penetrate opaque materials, and can be used to obtain fingerprint spectra whose characteristics depend upon intermolecular behaviour. Most art materials such as mercury sulphide used as a red pigment have characteristic fingerprint spectra in the $\mathrm{THz}$ region [5] and can be identified either in the transmission or reflection mode. Another important feature is that time domain spectroscopy using the $\mathrm{THz}$ pulse can reveal the internal structure of non-metal objects, such as the air gap between ceramic and resin. With these advantages, terahertz spectroscopy and imaging techniques are expected to become a new analytical method for heritage science applications, and there have been various attempts by using model art works [6]-[9]. We have also applied $\mathrm{THz}$ imaging to observe a historical tempera masterpiece and successfully obtained a non-invasive cross section revealing the painting layers from the wood support to the surface, including two gesso layers present in medieval panel paintings [10]. 
We have applied $\mathrm{THz}$ reflection imaging to a fragment of the wall painting from Dazhao Monastery (around $200 \mathrm{~mm}$ in height, and $250 \mathrm{~mm}$ in width), and have obtained a map of different pigments and its layer structure. This paper compares the $\mathrm{THz}$ reflection image of the wall painting fragment with $\mathrm{XRF}$, Raman spectroscopy, and near infrared imaging.

\section{EXPERIMENTS}

Figure 1(a) shows the fragment of wall painting from Dazhao Monastery, and points at the Raman spectra, shown in Figure $1(\mathrm{~b})$, that were obtained to identify pigments. Bright orange and red colours are recognised in several parts, and the other major colours are blue, white and yellow is recognized as the skin colour. Table 1 shows the list of estimated pigments from Raman spectra as well as XRF. On the basis of the spectral database (http://www.thzdb.org) containing spectra obtained with a Fourier Transform Infrared (FTIR) system, it is estimated that the $\mathrm{THz}$ reflections of lead-based pigments (minium and lead white) and HgS (cinnabar) should be especially strong. From the results of XRF, the pigments were considered as given in Table 1.

Spectra in $\mathrm{THz}$ region and $\mathrm{THz}$ reflection images in this paper were obtained by using a transportable THz-TDS system with rapid signal acquisition (Picometrix T-Ray 4000). The work-

(a) Visible image

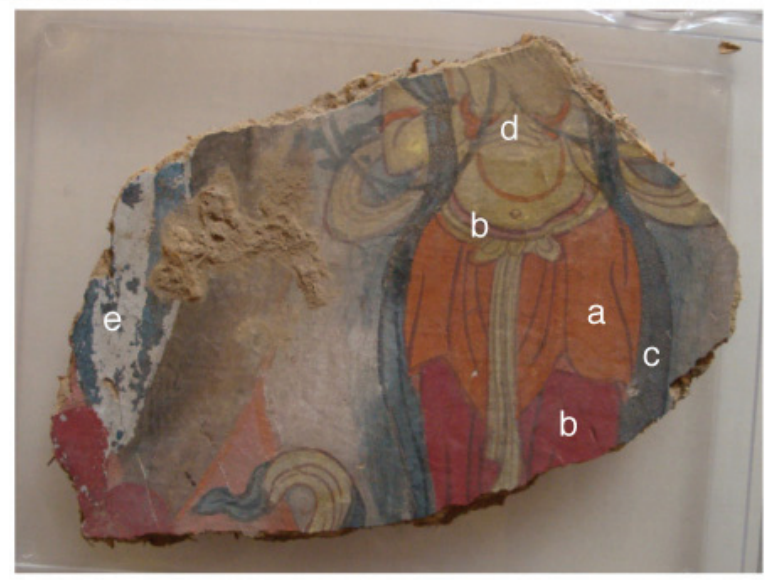

(b) Raman spectrosocpy analysis

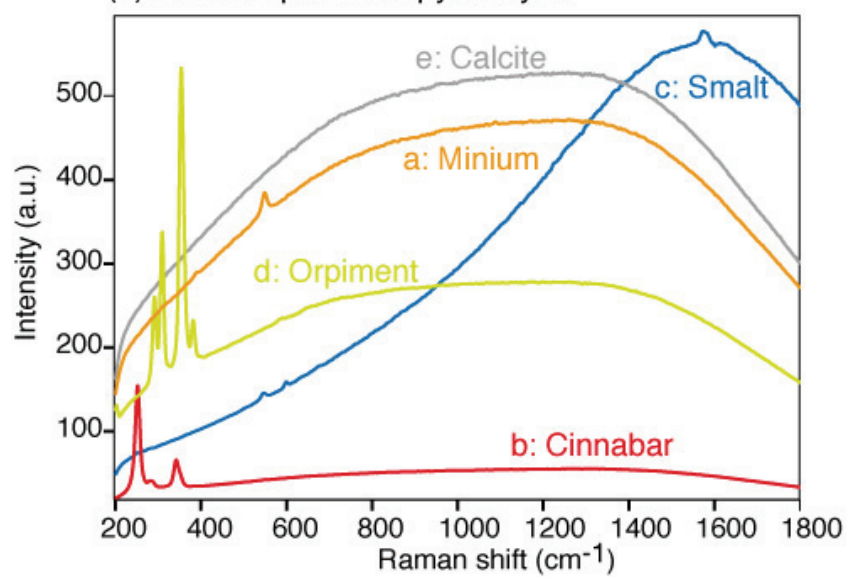

FIG. 1 Fragment of wall painting and Raman spectra of some points in the painting.

\begin{tabular}{|l|r|l|}
\hline Colours & Elements & Estimated pigments \\
\hline Blue & $\mathrm{Pb}, \mathrm{Ca}, \mathrm{Fe}, \mathrm{Si}, \mathrm{K}, \mathrm{Ca}$ & Smalt \\
Green & $\mathrm{Cu}, \mathrm{Fe}, \mathrm{As}$ & Malachite, Verdigris \\
Yellow & $\mathrm{As}, \mathrm{S}$ & Orpiment \\
White1 & $\mathrm{Pb}$ & Lead white \\
White2 & $\mathrm{Ca}, \mathrm{Al}, \mathrm{Si}$ & Calcite \\
Red & $\mathrm{Hg}, \mathrm{S}$ & Cinnabar \\
Orange & $\mathrm{Pb}$ & Minium \\
Dark orange & $\mathrm{Pb}, \mathrm{Fe}, \mathrm{Ca}$ & Minium, Red orche \\
\hline
\end{tabular}

TABLE 1 Pigments estimated in 2002.

ing frequency range was approximately from 0.2 to $1.4 \mathrm{THz}$ for this specimen which does not have very flat surface. InGaAs camera C10633-13 (900-1700 nm) of Hamamatsu was used to observe the near-infrared image for comparison. XRF mapping is also reorganised to confirm the findings by $\mathrm{THz}$ imaging.

\section{MATERIAL MAPPING}

Figure 2 shows the reflection spectra of estimated pigments acquired from a special supplier for conservators. Orange minium $\left(\mathrm{Pb}_{3} \mathrm{O}_{4}\right)$, red cinnbar $(\mathrm{HgS})$, and lead white $\left(2 \mathrm{PbCO}_{3} \cdot \mathrm{Pb}(\mathrm{OH})_{2}\right)$ have high reflectance. Calcite $\left(\mathrm{CaCO}_{3}\right)$ has relatively high reflectance comparing to other pigments: blue smalt (cobalt-glass), orpiment $\left(\mathrm{As}_{2} \mathrm{~S}_{3}\right)$, malachite $\left(\mathrm{Cu}_{2} \mathrm{CO}_{3}(\mathrm{OH})_{2}\right)$ and red orche $\left(\mathrm{Fe}_{2} \mathrm{O}_{3}\right.$, as a main component). Although the spectrum in reflection mode is affected by the surface conditions, it should contribute to distinguish a particular pigment by extracting the data at certain frequency range.

Figure 3 shows the $\mathrm{THz}$ reflection image compared with the visible image. As expected from the reflection spectra of estimated pigments shown in Figure 2, the orange minium and red cinnabar area exhibited high reflection. The white area in the centre of the fragment also reflects the $\mathrm{THz}$ waves, so that it is estimated as lead white. The yellow orpiment and blue smalt did not reflect $\mathrm{THz}$ waves. The top-left area where the clay remained on the surface appeared in dark. This is due to the scattering of $\mathrm{THz}$ waves at the surface. Here, there is an orange sash that exhibits no reflection in $\mathrm{THz}$ imaging, which

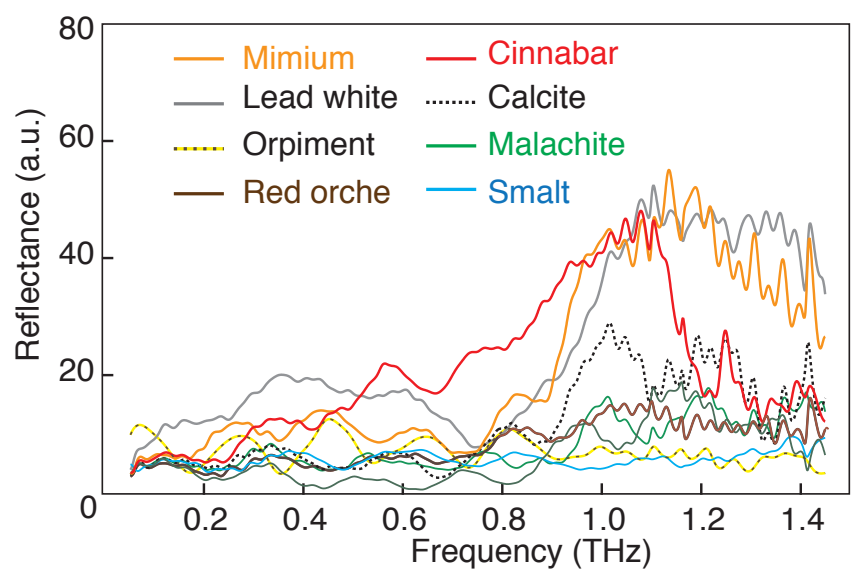

FIG. 2 Spectra of estimated pigments in reflection mode. 
(a) Visible image

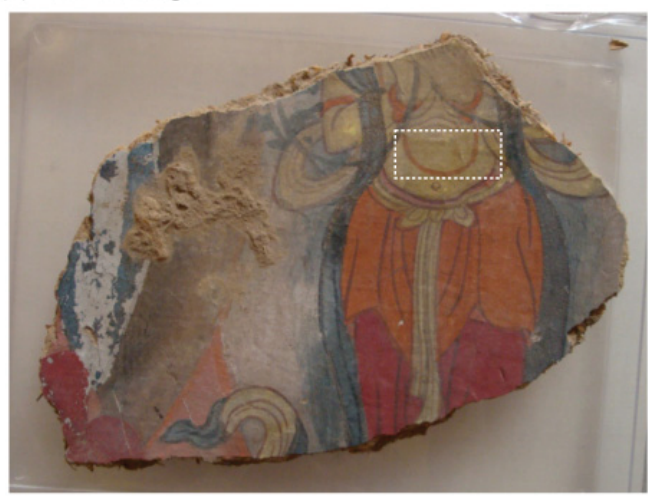

(b) THz reflection image

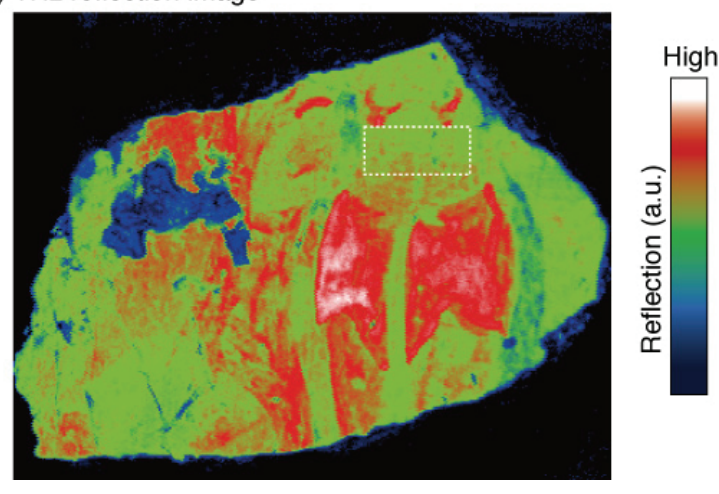

FIG. 3 Comparison between visible and THz reflection images of the wall painting.

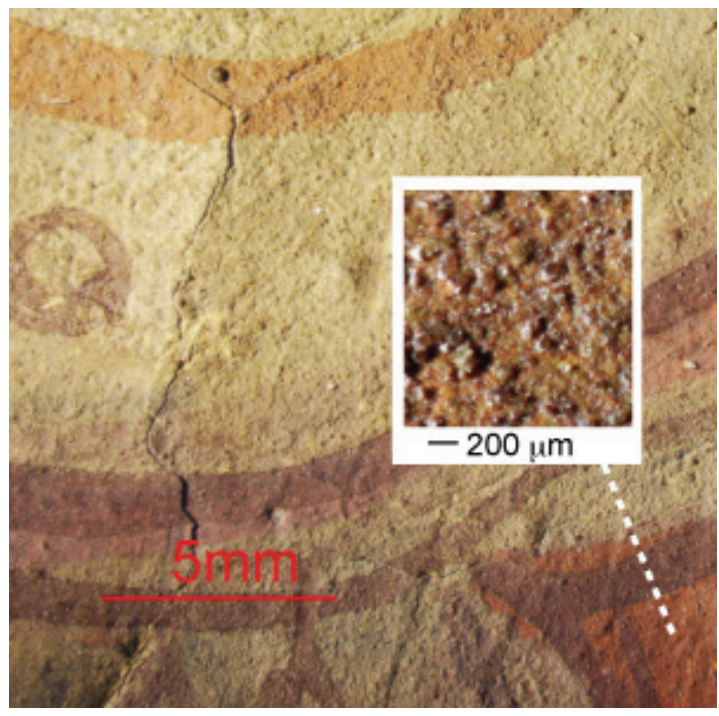

FIC. 4 Two orange pigments.

is marked in a white dotted line in Figure 3. The colour in the visible image is exactly the same as the other orange colours that exhibit extremely high reflection. We thus observed the surface by using a microscope to compare the grain size. As shown in Figure 4, the grain was not recognised in the orange colour of the sash at the waist line. On the other hand, for the other orange area, around "a" in Figure 1(a) for example, the grain size can be around 30-100 $\mu \mathrm{m}$ (inlet). Thus, the orange colour of the sash should be a type of organic dye that gives the same orange colour when it is painted over the base yellow colour.

We performed XRF measurement again to confirm the iden-

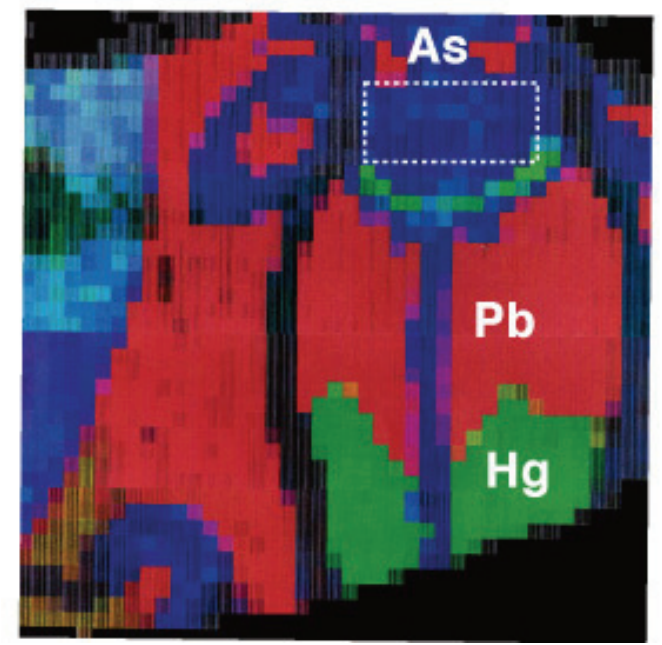

FIG. 5 Comparison between THz reflection image and element map (As, Pb, Hg) by XRF.

tification of the orange colour of the sash, and observed that no lead was there, but only arsenic appeared from the base skin colour. Therefore, the orange colour is highly likely to be a type of organic dye painted on the orpiment area. Figure 5 shows the XRF material map. It took days to perform XRF mapping of this fragment. THz imaging, on the other hand, can provide the distribution of different materials, in 10 minutes, although it will not be sufficient to identify all pigments, due to the lack of a spectral database and fundamental research on the spectra assignment in the $\mathrm{THz}$ region.

Here, the black line was not visible in the THz image because most of the carbon-based black pigments, such as lamp black, have high transmittance in the $\mathrm{THz}$ range. On the other hand, the absorption of near-infrared rays of carbon black is high, so that drawings by carbon black can be observed effectively as shown in Figure 6. Therefore, it is very important to use as many possible methods to analyse the artworks.

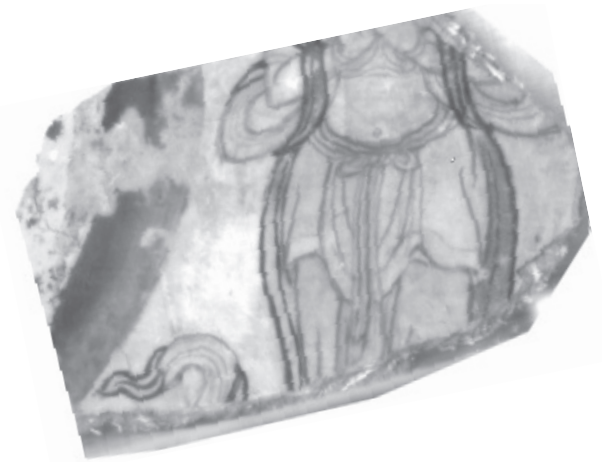

FIG. 6 Near-infrared image of the wall painting.

\section{NON-INVASIVE CROSS-SECTION IMAGING}

Time domain spectroscopy using $\mathrm{THz}$ pulses makes it possible to non-destructively observe the internal structure of opaque objects. Figure 7(b) shows a THz non-invasive crosssection along the red line in black and white $\mathrm{THz}$ image shown in Figure 7(a). Many cracks were recognised in Figure $7(a)$, and the depth of the crack from the surface could be 


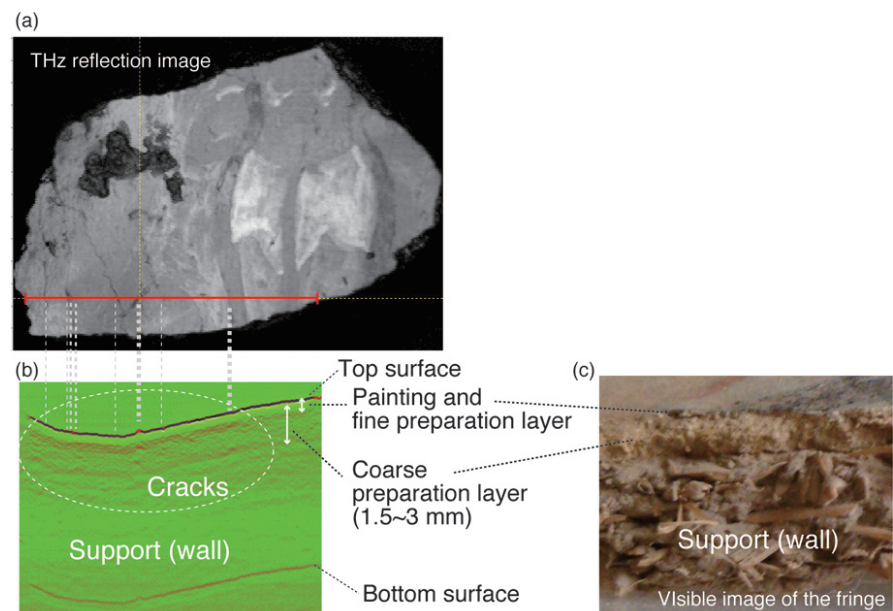

FIG. 7 THz reflection and non-invasive cross-section image.

estimated from Figure 7(b). The layer structure is also recognised in the non-invasive cross section, which is in good agreement with the visible layer structure at the fringe of the panel (Figure 7(c)). Since minium and cinnabar have high reflection, resulting in low signal penetration, the internal structure under the area painted with them was slightly vague. In practice, the preparation layer is uniform, and then the internal structure can be estimated by measuring other parts which has higher transmittance at the surface layer. When the sample is not a fragment, and cannot take a small piece from the artworks, only $\mathrm{THz}$ imaging can reveal the internal structure of the artworks.

\section{CONCLUSIONS}

We observed a fragment of a wall painting by using $\mathrm{THz}$ time domain imaging, in addition to common analysis techniques, such as X-ray fluorescence. $\mathrm{THz}$ imaging discovered that two materials were used in one colour and it has two preparation layers, non-invasively, in a short time. $\mathrm{THz}$ imaging can also provide practical information for conservators, such as the depth of cracks from the surface. From these results, it is clear that the THz spectroscopy and imaging can provide complementary data to multi-spectral approach for cultural heritage science.

\section{References}

[1] D. Pinna, M. Galeotti, and R. Mazzeo, Scientific Examination for the Investigation of Paintings. A Handbook for Conservator-Restorers (Centro Di, Firenze, 2009).

[2] Y. Kouzuma, T. Koezuka, M. Sawada, X. Du, and X. Du, “Non destructive analysis of wall paining fragment of Dazhao Monastrey" P. Ann. Meet. J. Soc. Cons. Cult. Prop. (2003).

[3] D. M. Mittleman, Sensing with terahertz radiation (Springer, Berlin, 2003).

[4] M. Tonouchi, "Cutting edge terahertz technology" Nat. Photonics 1, 97-105 (2007).

[5] K. Fukunaga, Y. Ogawa, S. Hayashi, and I. Hosako, "Application of terahertz spectroscopy for character recognition in a medieval manuscript" IEICE Electron. Expr. 5, 223-228 (2008).

[6] W. Köhler, M. Panzer, U. Klotzach, S. Winner, M. Helm, F. Rutz, C. Jördens, M. Koch, and H. Leitner, "Non-destructive investigation of paintings with THz-radiation" P. Europ. Conf. N.-Destr. Test. P181, (2006).

[7] K. Fukunaga, Y. Ogawa, S. Hayashi, and I. Hosako, "Terahertz Spectroscopy for Art Conservation" IEICE Electron. Expr. 4 258-263 (2007).

[8] J. B. Jackson, M. Mourou, J. F. Whitaker, I. N. Duling III, S. L. Williamson, M. Menu, and G. A. Mourou, "Terahertz imaging for non-destructive evaluation of mural paintings" 0pt. Commun. 281, 527-532 (2008).

[9] A. J. L. Adam, P. C. M. Planken, S. Meloni, and J. Dik, “Terahertz imaging of hidden paint layers on canvas" Opt. Express 17, 34073416 (2009).

[10] K. Fukunaga, and M. Picollo, "Terahertz spectroscopy applied to the analysis of artists materials" Appl. Phys. A.-Mater, in print (2010). 